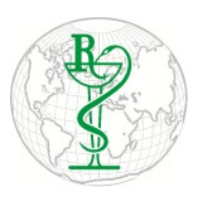

INDO GLOBAL JOURNAL OF

PHARMACEUTICAL SCIENCES

ISSN 2249- 1023

\title{
Formulation and Evaluation of Antibacterial Herbal Mouthwash Against Oral Disorders
}

\author{
Shafi Ahmad, Saloni Sinha, Smriti Ojha * , Hina Chadha, Babita Aggarwal, Ajeet, SeemaMahor Jain, \\ Meenu
}

School of Pharmaceutical Sciences, Vishveshwarya Group of Institutions, Greater Noida (UP), 203207, India

\begin{abstract}
Address for Correspondance Smriti Ojha, smriti.tripathi

@,vgi.ac.in

Received:

16.01.2018

Accepted:

11.02.2018

ABSTRACT: The objective of present work is to formulate and evaluate herbal mouthwash and to evaluate its effectiveness against microbial load of oral cavity. The plant materials were collected and extracted for water soluble ingredients. Prepared mouthwash was further evaluated for its physicochemical properties and antimicrobial activity. The present mouthwash possesses a good antibacterial property. The results of stability study also confirm the effectiveness of preparation. Present mouthwash is a liquid preparation which normally contains antibacterial and antiseptic agents. These solutions can be used to reduce the microbial growth in the oral cavity and may also be given for other reasons like for their analgesic action, anti-inflammatory property or anti-fungal activity. (C) 2018 iGlobal Research and Publishing Foundation. All rights reserved.

Cite this article as: Ahmad, S.; Sinha, S.; Ojha, S.; Chadha, H.; Aggarwal, B.; Ajeet; Jain, SM; Meenu. Formulation and evaluation of antibacterial herbal mouthwash against oral disorders. Indo Global J. Pharm. Sci., 2018; 8(2): 37-40.
\end{abstract}

Keywords Mouthwash; Antibacterial; Plaque; Periodonta.

\section{INTRODUCTION}

Dental plaque is a complex biofilm that accumulates on the surface of teeth, containing more than 500 bacterial species $[1,2]$. The dental plaque is produced by initial colonizing bacteria in the salivary film of enamel, followed by secondary colonization through antibacterial adhesion [3-5]. Prenominal diseases affect the supporting tissues of teeth. Gingivitis, the mildest form of prenominal disease is generally caused by insufficient oral hygiene. Gingivitis is characterized by inflammation and bleeding of the gum. The main cause of gingivitis is plaque that forms on the surface of teeth and gums. As a main stay of maintain oral hygiene, mechanical plaque control measures are used. Mechanical plaque control techniques are time consuming and require motivation and skill to be performed well; hence antimicrobial agents have been employed extensively as an adjunct to mechanical cleaning. Several antimicrobial chemical agents such as chlorhexidine metronidazole etc. have been used. However, these artificial drugs have unpleasant side effects, so researchers are trying to pay more attention to herbal drugs. Plants and plant's isolates demonstrates effects that are immune enhancing, anti-inflammatory, anticancer etc. [6, 7].

Neem have Antimicrobial, fungicidal, anti-inflammatory property. Neem bark and leaf are used to treat and prevent the onset of many dental disorders since ancient time. Clove shows analgesic and anti-inflammatory property. It is used in 
Indo Global Journal of Pharmaceutical Sciences, 2018; 8(2): 37-40

temporary treatment of toothache. It proved to reduce local inflammation in oral cavity. Cinnamon has antioxidant property, bactericidal and anti-inflammatory property. It also gives a pleasant flavor to many oral formulations. It is reported to protect dental health and freshens breath naturally. Glycirrhiza is an anti-inflammatory, analgesic and demulcent. This herb is reported to promote oral health conditions.

The antibacterial and antimicrobial properties of the mouthwashes can prevent the growth of cavity causing bacteria, reduce plaque, fight bad breath and keep the teeth and gums strong and healthy. Salt heals mouth sores because of producing exosmosis is improves swollen gum conditions of many periodontal disorders. Saline has a mechanical cleansing action and an antiseptic action as it is a hypertonic solution in relation to bacteria, which is undergo lysis. The heat of solution produces therapeutic increase in blood flow (hyperemia) to the surgical site, promoting heating[1].It also encourages drainage of pulse from dental abscesses[8].

\section{MATERIALS AND METHODS}

\section{Collection of Plants}

Leaves, bark and stem of Azadirachta indica (Neem), buds of Eugenia caryophyllus (clove), bark of Cinnamomum zeylanicum (cinnamon), and root Glycyrrhiza glabara (Liquorice) were randomly collected from mature plants.

\section{Extraction process}

The collected plant materials were washed with sterile water, shadow dried, pulverized and stored in air-tight bottles separately. The Aqueous extract of each plant material was prepared by soaking the powdered plant parts in sterile distilled water and maintained in Incubator at $37^{\circ} \mathrm{C}$ for $72 \mathrm{~h}$. The herbal extracts were filtered using Whatmann filter paper; marc was washed with $10 \mathrm{ml}$ of sterile distilled water and pressed.

\section{Formulation of herbal Mouthwash}

The herbal Mouthwash was prepared by the formula given in table 1 . Salt solution was made by preparing $1 \% \mathrm{w} / \mathrm{v}$ solution of salt in sterile water. Then all the extracted ingredients are mixed in a fixed ratio.

\section{The ingredients used in this preparation are- Evaluation of herbal mouthwash}

Color and Odour: Physical parameters like odour and color were examined by visual examination [9].

pH: $\mathrm{pH}$ of prepared herbal mouthwash was measured by using digital $\mathrm{pH}$ meter. The $\mathrm{pH}$ meter was calibrated using standard buffer solution about $1 \mathrm{ml}$ of mouthwash was weighed and dissolved in $50 \mathrm{ml}$ of distilled water and its $\mathrm{pH}$ was measured[10].

Test for microbial growth in formulated mouthwash- The formulated mouthwash was inoculated in the plates of agar media by streak plate method and a control was prepared. The plates were placed in the incubator and are incubated at $37^{\circ} \mathrm{C}$ for 24 hours. After the incubation period plates were taken out and checked for microbial growth by comparing it with the control [10].

Stability Studies- The formulation and preparation of any pharmaceutical product is incomplete without proper stability studies of the prepared product. This is done in order to determine the physical and chemical stability of the prepared product and thus determine the safety of the product. A general method for predicting the stability of any product is accelerated stability studies, where the product is subjected to elevated temperatures as per the ICH guidelines. A short term accelerated stability study was carried out for the period of 3 months for the prepared formulation. The samples were stored at under the following conditions of temperature as $3-5^{0} \mathrm{C}, 25^{\circ}$ $\mathrm{C} \mathrm{RH}=60 \%, 40^{\circ} \mathrm{C} \pm 2 \% \mathrm{RH}=75 \%$. Finally the samples kept under accelerated study were withdrawn on monthly intervals and were analyzed [11].

Table 1. Formulation of herbal mouthwash

\begin{tabular}{|l|l|l|l|l|l|}
\hline S. No & INGRIDIENTS & Botanical name & Plant Part & Functions & PERCENTAGE \\
\hline 1 & Neem & Azadiracta indica & Bark, Stem & Antimicrobial & $30 \%$ \\
\hline 2 & Clove & Eugenia caryophyllus & Flowder Bud & Analgesic, Anti-inflammatory & $30 \%$ \\
\hline 3 & Cinnamon & Cinnamomum zeylanicum & Bark & Flavouring agent, Bactericidal & $20 \%$ \\
\hline 4 & Liquorice & Glycyrrhiza glabara & root & Demulscent, sweetwner & $10 \%$ \\
\hline 5 & Salt & - & & Osmolytic preservative & $10 \%$ \\
\hline 6 & Sodium benzoate & - & & Preservative & $0.2 \%$ \\
\hline
\end{tabular}




\section{Indo Global Journal of Pharmaceutical Sciences, 2018; 8(2): 37-40}

\section{In vitro antibacterial activity}

In vitro antibacterial activity was performed on isolated colonies of Streptococcus mutans. The Agar well diffusion technique was used for determining the zone of inhibition and minimum inhibitory concentrations (MIC). The strains of S. mutans were inoculated in prefabricated blood agar plate. Plates were dried and 4 wells were made with the help of 6 mm agar well cutter. $20 \mu \mathrm{l}, 40 \mu \mathrm{l}, 60 \mu \mathrm{l}, 80 \mu \mathrm{l}$ of prepared mouthwash was loaded in all the respective wells. The agar plates were kept undisturbed to allow the passive diffusion of herbal mouth wash into the agar culture medium. Then the plates were incubated at $37^{\circ} \mathrm{C}$ for 24 hours. The zone of inhibition was calculated in $\mathrm{mm}$.

\section{RESULTS AND DISCUSSION}

The $\mathrm{pH}$ of the formulation was found to be 6.1. As the skin is having an acidic $\mathrm{pH}$ around 5.5 this $\mathrm{pH}$ range of the formulation is suitable for oral disorders. The formulation was found to be free from heavy metals. The formulation was free from microbes as they have not produced any microbial growth when they got inoculated in the agar medium [10].This mouthwash is a purely herbal prepared without the addition of any kind of alcohol and any other additives as other products found in the market. The formulation was undertaken stability studies for physical and chemical change. No considerable variations in properties of the formulation were observed [11]. The results of stability stability studies are shown in the given table 2.

Alcohol consumption as well as alcohol and tobacco use are known risk factors for head and neck cancers [12]. It has always been the question of whether use of alcohol containing mouthwash increases the risk of cancer[13].

When used in mouthwashes antimicrobial ingredient like neem, clove and other essential plant extracts have been found to reduce plaque and gingivitis when combined with daily brushing and flossing. Volatile sulfur compounds are the major contributing factor to bad oral odour. They arise from a variety of sources that is breakdown of food, dental plaque and bacteria associated with oral disease[14].

The antibacterial acivity was evaluated by agar diffusion method for different concentrations of mouthwash. The result of zone of inhibition for S.mutans was found to be $15 \mathrm{~mm}$ for $80 \mu \mathrm{l}, 12 \mathrm{~mm}$ for $60 \mu \mathrm{l}, 10 \mathrm{~mm}$ for $40 \mu \mathrm{l}$ and $9 \mathrm{~mm}$ for 20 $\mu \mathrm{l}$ respectively and $20 \mathrm{~mm}$ for $80 \mu \mathrm{l}, 20 \mathrm{~mm}$ for $60 \mu \mathrm{l}, 16 \mathrm{~mm}$ for $40 \mu \mathrm{l}$ and $12 \mathrm{~mm}$ for $20 \mu \mathrm{l}$ respectively for $\mathrm{S}$. salivarius. These results showed that the herbal mouthwash has significant antibacterial activity and the present preparation is able to inhibit bacterial growth in oral cavity. The association of oral microbial load on oral diseases is well established [15].

Table 3. Result of agar well diffusion antibacterial assay

\begin{tabular}{|c|c|c|c|c|}
\hline Organism & \multicolumn{4}{|c|}{ Zone of inhibition (mm) } \\
\hline \multirow{2}{*}{ S. mutans } & $20 \mu \mathrm{l}$ & $40 \mu \mathrm{l}$ & $60 \mu \mathrm{l}$ & $80 \mu \mathrm{l}$ \\
\cline { 2 - 5 } & 9 & 10 & 12 & 15 \\
\hline S.salivarius & 12 & 16 & 20 & 20 \\
\hline
\end{tabular}

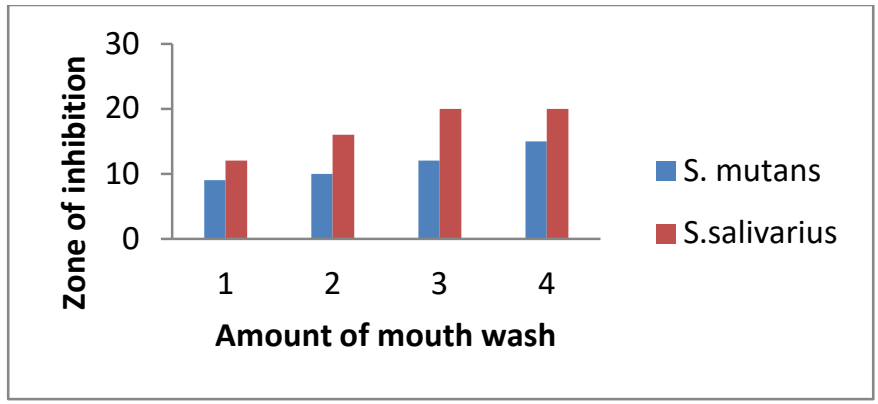

Fig. 1.Result of agar well diffusion antibacterial assay

Table 2. Results of stability study of herbal mouthwash

\begin{tabular}{|c|c|c|c|c|c|}
\hline \multirow[t]{2}{*}{ TEMPERATURE } & \multirow[t]{2}{*}{ EVALUATION PARAMETERS } & \multicolumn{4}{|c|}{ OBSERVATION (Months) } \\
\hline & & 0 & 1 & 2 & 3 \\
\hline \multirow[t]{3}{*}{$3-5^{\circ} \mathrm{C}$} & Visual Appearance & Light brown & Light brown & Light brown & Light brown \\
\hline & Phase Separation & Nil & Nil & Nil & Nil \\
\hline & Homogeneity & Good & Good & Good & Good \\
\hline \multirow{3}{*}{$\begin{array}{c}\text { Room Temperature } \\
\left(25^{\circ} \mathrm{C} \mathrm{RH}=60 \%\right)\end{array}$} & Visual Appearance & Light brown & Light brown & Light brown & Light brown \\
\hline & Phase Separation & Nil & Nil & Nil & Nil \\
\hline & Homogeneity & Good & Good & Good & Good \\
\hline \multirow[t]{3}{*}{$40^{\circ} \mathrm{C} \pm 2^{\circ} \mathrm{C} \mathrm{RH}=75 \%$} & Visual Appearance & Light brown & Light brown & Light brown & Light brown \\
\hline & Phase Separation & Nil & Nil & Nil & Nil \\
\hline & Homogeneity & Good & Good & Good & Good \\
\hline
\end{tabular}


Indo Global Journal of Pharmaceutical Sciences, 2018; 8(2): 37-40

Herbal mouthwashes can temporarily mask bad odour and provide a pleasing flavor. Herbal mouthwashes with therapeutic agents like antimicrobials, however, maybe effective for some long term control of bad odour.

Gargling is a condition or process where the head is tilled backwards which allows the mouthwash to sit in the back of the mouth during exhalation of air, which causes bubbling of liquid [15]. Herbal formulations are safe to use as a gargle also as its systemic availability in traces does not cause any side effects.

\section{CONCLUSION}

The present liquid herbal mouthwash can work in long way to help people to get rid of bad breath and many oral disorders. Besides we can be rest assured and take comfort in the fact that there aren't any unhealthy ingredients present in this preparation. The physicochemical evaluation results confirm that the colour and odour of present herbal formulation is acceptable with a pleasant odour and a better after effects.

The results of zone of inhibition also confirmed that this herbal mouth rinses was found to be a potent plaque inhibitor, and were preferred by the patients for its taste, convenience of use and test duration in their mouth after rinsing. Thus, these can be used as an adjunct to mechanical therapy for treating plaque induced gingivitis. Present study has an important impact in order to create an effective and inexpensive herbal oral health intervention for low social economic communities. However this study was short-term study so long term studies are required with larger. The natural herbs used in present formulation have been medicinally proven to prevent the problem of oral hygiene and bad breath. Since years and decades, these herbs have been known for working wonders as reflected in many research findings. Person can easily rinse his mouth using this herbal mouthwash and stay clear of wide variety of oral health issues.

\section{CONFLICST OF INTEREST}

The authors declare that there is no conflict of interest to reveal.

\section{REFERENCES}

[1] Matthews R W, Hot salt water mouth baths, British Dental Journal. 2003, 195 (1); 3-3.

[2] F.M Viera, M.C Macial, F.R Nascimento and V.P Rodrigues, Plant species used in dental desease: activity evaluation, Journal of ethanopharmacology. Vol. 155 (3), 1441-1449, 2014.

[3] Kumar P, Ansari S.H,Ali .J . Herbal remedies for the treatment of pridental disease: A patient review. Recent pat drug deliver formula 2009;3:221-8.

[4] Rao N.J. Subhas K.R, Kumar K.S. Role of phytotherapy in gingivitis, a review. J pharmacol 2012; 8:1-5.

[5] Clive E, Paul S, Minor illness or major disease?,The clinical pharmacist in the community $\left(4^{\text {th }}\right.$ edition $)$. Pharmaceutical press, 223. [6] Shubhangi E S, Monali D T,Journal of scientific and innovative research 2016; 5(4): 149-151.

[7] Sujith S N, Molly M, Sereena K.Int. J.of Pharm. And Clin. Sci., 2012;1(4): 1362-1368.

[8] ICH Harmonized Tripartite Guidelines, Stability Testing of New Drug Substances and Products, ICH Committee. Federal register 2003:68

[9] Chi AC, Day TA, Neville BW. Oral Cavity and oropharyngeal squamous cell carcinoma- an update.CA Cancer J Clin 2015;65(5); 401-21

[10] Weaver A, Fleming SM, Smith DB. Mouthwash and oral cancer; Carcinogen or coincidence? J Oral Surg 1979;37(4) : 250-3

[11] Blom T, Slot DE, Quiryen M, Van der Weijden GA. The effect of mouthrinses on oral malodour; a systemic review .Int J Dent Hyg 2012;10(3): 209-22

[12] Chitsazi M, Shirmohammadi A, Balayi E. Effect of herbal and chemical mouth-rinses on periodontal indices; comparison of matrica, persica and chlorhexidine. J Dent Shiraz Univ Med Sci. 8(4), 2008; 54-60.

[13] Geetha R.V, Anitha Roy. In Vitro Evaluation of Anti bacterial Activity of Ethanolic root extract of Glycyrrhizaglabra on Oral microbes. Int. J. Drug Dev. \&Res., October-December 4(4), 2012, 161-165.

[14] L.G.Vijayaalakshmi, R.V.Geetha. Comparison of Herbal Mouth Wash with Conventional Mouth Wash in Use in Reducing Streptococcus Mutans -An In vitro Study. J. Pharm. Sci. \& Res. Vol. 7(7), 2015, 485-486.

[15] Renuka s, Muralidharannp. Comparison in benefits of herbal mouthwashes with chlorhexidine Mouthwash: a review. Asian J Pharm Clin Res, Vol 10, Issue 2, 2017, 1-5.

Indo Global Journal of Pharmaceutical Sciences( ISSN 22491023 ; UGC Journal No.: 44477; CODEN- IGJPAI; NLM ID: 101610675) indexed and abstracted in EMBASE(Elsevier), UGC Journal List, National Library of Medicine (NLM) Catalog, Elsevier( EMBASE), ResearchGate, Publons, CAS (ACS), Index Copernicus, Google Scholar and many more. For further details, visit http://iglobaljournal.com 